tinuous chain of mechanism, the breaking of any one ink of

In the Murray automatic system all the received messages are first recorded at a high speed as perforations in paper tape, and from this perforated tape the messages are afterwards printed automatically. In the Murray multiplex a different kind of receiving perforator is provided. This instrument is shown in Fig. 16. It is essentially a Murray keyboard perfora tor tilted up on end and with the keys omitted. In place of the keys there are five small magnets which do the work of the keys-that is to say, they contro selectively five small steel rods, which determine the holes to be punched in the paper tape. These fiv magnets correspond exactly with the five setting mag. nets of the multiplex printer (see Fig. 8). Each of these five setting magnets of the receiving perforator are placed in series with the corresponding one of the five setting magnets of the printer. The punching magnet of the receiving perforator is operated by the same impulse as that operating the printing magnet (Fig. 8) of the printer. On the printer there is provided a switch to throw the receiving perforator into or out of action by means of a signal from the distant station. If the sending operator at the distant station $\mathrm{A}$ has a message which requires to be transmitted at station B. This puts the receiving perforator in signal which throws over the switch in the printer at station B. This puts the receiving perforator in action. The message is then recorded as perforations as it is being printed in page form by the printer. A the end of every message the page signal, in addition to turning up a fresh telegraph form, automatically cuts out the receiving perforator. Consequently onl messages requirifig retransmission are perforated, an the sending operator has control over this operation at the distant station. As there is a printed message produced at the same time as the perforated tape a glance at the printed message will show whether it has been correctly received. If it has been received correctly, then it can be automatically retransmitted to its destination by means of the perforated tape. T the message has not been accurately received, it can be corrected and sent in the ordinary way by manua instead of automatic retransmission. That is to say it can be perforated again correctly on a keyboard perforator. In this respect the receiving perforato and tape retransmission present a decided advantage over the methods of direct communication between several towns, because any breakdown of the receiving perforator leaves all the ordinary working mechanism intact, and transmission can proceed in the ordinary way. This multiplex rẹceiving perforator offers two main advantages in addition to that just mentioned, namely, (1) the message is printed and also perforated mission are perforated. The others are printed only. PREPARATION OF MFSSAGE FORMS.
Pe

It is obvious that in a page-printing telegraph printing direct from the receivea signals, it is necessary to have some positive and automatic method of throwing out the finished message and feeding up a new message form to the right printing point. This may be done in two ways: (1) By feeding from a pile of cut forms, or (2) by means of a continuous roll of message forms. During recent years a number of devices have been perfected for feeding in separate sheets of paper one after another automatically into printing machines. There are undeniable advantages in this cut form plan, but the cross motion of the typewriter carriage presents serious obstacles to its employment in printing telegraphs. There is also the considera tion that occasionally a message form may fail to feed into the printer, and the corresponding message would not be recorded. This would entail delay and repetition, and in some cases confusion and possible loss of a message or delivery of a message twice over. The continuous roll feed is free from these objections, but it entails preparation of some kind beforehand. Some slit or perforation has to be made in the paper band at the top of each message form to ensure positive feeding in of the forms to the right printing point. The messages have also to be cut apart with a pair of scissors or by other means. The arrangement adopted in the Murray multiplex may be described as a compromise between the two methods. Cut forms are employed, but they are lightly tacked together with dextrin so as to overlap. They are also perforated along their sides like cinematograph films, so as to ensure positive feeding up to the point for starting the message. This arrangement works well, and it has the advantage that the receiving operator has merely to pull off the messages as they are finished. There is an absolute minimum of trouble in this respect. For the preparation of the message rolls beforehand, a punching tool is employed, which perforates 8 to 10 messages simultaneously. This is a quick and simple operation and a large number of messages can be perforated at trifling cost. Pasting the messages together into continuous rolls also presents no difficulties. The work can be done by a boy very rapidly by hand on a table without any mechanism; and in cases where large quantities are needed, a machine has been made to turn out the rolls quickly and cheaply.

$$
\text { TIME STAMP AND PRESS COPIER. }
$$

In the case of printing telegraphs handling a large number of messages, a time stamp saves a good deal of labor, and such an instrument is of special value in the case of a system like the Murray multiplex, wher there is a possibility of one receiving operator attending to two printers, each producing 80 or more mes sages an hour. There is now at least one good time tamp on the market, and it is probable that such in struments will come into extensive use in connection with printing telegraphs during the next ten years. The time stamp will print on the telegrams instantly the date and time of reception, the number of the circuit, and any other particulars, including a number or other mark identifying the operator receiving and checking the messages. Actual experience has sh Jwn that an operator can easily check 120 messages in hour, and it is possible to check 150 an hour. With the aid of a time stamp it is believed that it would be easy to check 150 to 130 messages an hour. That is to say, except during times of great pressure, on operator would be able to attend to two multiple printers, each turning out about 80 messages an hour. There are a number of excellent wet-press copiers now in commercial use, and in time wet-press copying will overcome the trouble about keeping a copy for record of telegrams issued to the public. With a good multiplex printing telegraph such as that just described, and with a time stamp and press copying. the labor cost of telegraphy will be reduced to about the lowest point possible.

RESUL'TS WITH MURRAY MULTIPLEX.

It is too early yet to say positively what results can be obtained with the new Murray multiplex system, especially as there are still a number of detail improvements to be made. A complete installation has only recently been completed for the British Post Office, and is now being installed between London and Manchester. Prior to this, an experimental set, giving one transmission only, was made by the British Post Office, and tried for about six months between London and Birmingham. The results were surprisingly good. The sending operators were two girls without previous experience on typewriter keyboards, and yet within one month they were each punching 40 to 45 messages an hour. After about three months practice each of these two girls succeeded in perforating 100 messages in one hour. Excluding severa. days when there were interruptions and breakdown due to imperfections in the experimental apparatus, and excluding several days when traffic was light, the average number of messages on the one channel of transmission of the multiplex was over 80 per hour. On several days during busy hours the average ex ceeded 100 messages an hour. On one day, for instance, during three consecutive hours from $10 \mathrm{~A}$. M. to 1 P. M., the numbers were 104,126 , and 102 mes sages per hour.

\title{
The Career of the Investigator.
}

\section{By Professor W. B. Cannon, of Harvard University}

[In addressing the graduating class of the Yale Medical School last June, Prof. Cannon drew the attention of his listeners to the increased variety of services which at the present day invite the medical graduate to devote to them his lifework. Of the several careers thus thrown open, the speaker selected for detailed consideration that of the investigator, regarding which he quotes the beautiful words of Harvey: "Truly in such pursuits it is sweet not only to toil but to grow weary." We take a special pleasure in reproducing here from "Science" the essence of Prof. Cannon's inspiring address.-ED.]

The investigator is first of all one who thinks as much of what we are ignorant of as he does of what has already been made clear. His chief interest is in the territory which has not yet been trav-
erse. Indeed he is to be classed with explorers and pioneers.

For such men the complacent contemplation of things accomplished is intolerable-they chafe under the routine of established ways, and find the satisfaction of life in adventures beyond the frontiers. Harvey, among the first of modern discoverers, expressed the spirit of research when he wrote:

"It were disgraceful, with this most spacious and reward ever exceeds the promise, did we take the reports of others upon trust, and go on coining crude problems out of these, and on them hanging knotty and captious and petty disputations. Nature is her self to be addressed; the paths she shows us are to be. boldly trodden; for thus, and while we consult our proper senses, from inferior advancing to superior levels, shall we penellatr at length into the heart of her mystery."

And in another plate he wrote.

"Truly in such pursuit it is sweet not merely to toil, but even to grow weary, when the pains of dis

\section{covering are}

iscovery." concerning the world about us, a curiosity which most of us gradually lose as we fit ourselves into the social conventions. The investigator is one, how ever, in whom this natural curiosity still persists. He has never got past the annoying stage of asking "Why?" The events occurring on every side which are matters of course to most men, startle him into wonderment. Why does the spinning top not fall? Why do animals breathe faster when they run? Why does disturbed water take the form of waves? Why do roots grow downward? Why does the mouth become dry when one speaks in public? Such are the questions that arise. The answers to them may be incalculably valuable to mankind. The microscope revealed to Pasteur strange organisms in bad-tasting wines. Why may not the disease of the wine, he wines. Why may not the disease of the wine, he
asked himself, be due to the growth of these unusual germs within it? And later when he found germs also in silk worms, the further question was sug. gested, Why may not animals likewise become dis eased in exactly the same manner? Whether the surmises of the investigator are true, the testimony of other men usually does not tell. He must turn to nature herself and put the idea to the test of observation and experiment.

This process of scientific inquiry involves peculiar qualifications which can not be disregarded by any one who thinks of trying it. Research implies in the first place seeking again over a region which has been previously traversed in order to learn what other men have done and the point where their labors ender. To make progress sure, therefore, previous records just tribute to those who have labored before has this seldom led to fruitless effort or to vain repetition of work already well done. Marking the boundaries demands, then, a scholarly acquaintance with earlie discoveries; and the painstaking methods of the scholar must be used.

An ingenious and inventive imagination is a secon requirement. It serves to indicate. where the problem ie and also to suggest possible methods for solvin them. The mind must be hospitable to all ideas thus presented, and yet it must receive them with skeptical scrutiny. By critically considering a plan for solving a problem it is of ten possible to select central tests, which are strategically related to the logic of the entire research. The physiologist Goltz is said to hav done his most important work while fishing, for : employed that time in devising the crucially significant experiments.

Not all inquiries, however, can be ended by a relatively small number of crucial tests. Some investigations, like the important breeding experiments of De Vries, require years before they can be brought to conclusion. Patience and an enthusiasm which is intelligently persistent are therefore essential qualt ties for the man in quest of new truths. The hopeful spirit is especially needed when, at the end of a lon search, the investigator finds that he has only his labor for his pains-when his leading idea has provar to be false. That disheartening event is what Huxley called the tragedy of science-"the slaying of a beautiful hypothesis by an ugly fact."

The very soul of research, finally, is the highest degree of honesty. The investigator should see clearly and accurately with an eye single to the truth. H has to consider not only the observations which fit his theory, but any others as well. The erratic cases invari ake troulle, but they are often disguised 'hey may indeed be of far greater mo those which have been anticipated, for they int the way to entirely unsuspected facts. 
In my early sudies on digestion I well remember how much I was annoyed by the repeated failure of som animals to show any signs of digestive activity durin the period of observation. You can imagine how suddenly my vexation changed to deep interest when the troublesome inhibition was found to be an accompaniment of fright or anxiety which these animals showed while being looked through with the X-rays.

After the investigator has completed his examin tion of a group of questions which have intereste him, his leading idea, his tests and his results must be described with scrupulous exactness. In thus re porting his work he should strive to be like clearest crystal, receiving the light and

tinged by any trace of color.

Scientific activity implies, of course, thorough disinterestedness. The investigator asks no favors all renders none. Any intimation that he act as a re tainer or special pleader, any hint or suggestion that he injure cherished traditions, is a step toward th confinement of the free spirit of intellectual inquiry. Rather than surrender that freedom of inquiry or the right of untrammelled announcement of fresh discoveries, men of science have in the past submitted to tortures and painful death, and you may be sure that if need be, they will be ready to sacrifice themselves again. So exalted is the regard in which the man of science holds the ideal to which his life is devoted that he would find in these words of Fichte his solemn pledge:

"To this I am called, to bear witness to the Truth. My life, my fortunes, are of little moment; the results of my life are of infinite moment. I am Priest of Truth; I am in her pay; I have bound myself to do all things, to venture all things, to
suffer all things for her. If I should be persecuted suffer all things for her. If I should be persecuted
and hated for her sake, if should even meet death and hated for her sake, if should even meet death
in her service, what wonderful thing is it I shall have done-what but that which I clearly ought to do?"

The satisfactions of a life devoted to investigation, like the satisfactions of other careers, arise from the profitable use of one's powers. The peculiar power which are needed for research 1 have just described. The employment of these powers in perfect freedom and the immeasurably important results that flow and the immeasurably important results that flow
therefrom, render the satisfactions of productive scholarship especially keen. These satisfactions w may now consider in relation to the special qualifications of the investigator.

The requirement that the investigator learn what other men have done before him in the field he seeks to enlarge gives him an unusual realization of tho part he may be playing in the promotion of natural knowledge. Knowledge grows like the picture in tne knowledge. Knowledge grows like the picture in tne dissected puzzle. Every addition must fit the part
already arranged in order to possess significance, and also every addition makes possible the fitting of new parts whose positions in the enlarging picture be come thereby suddenly revealed. One of the delights of research, therefore, is the sense that every bit of new knowledge finds its place in the structure of truth, and that sooner or later it will be required for the further building of that structure. The relation which the fresh contribution bears to that already which the fresh contribution bears to that already
established, the discoverer clearly sees; what relation it will certainly bear to further contributions he ma never know. How little did the men who studie the minute differences among mosquitoes, and wh recorded the breeding habits of those insects realize their important rôle in abolishing the pestilence of yellow fever, and in bringing about the immense social and political changes which will result from that conquest.

Because every discovery becomes the basis for fur ther discovery the imagination of the investigator constantly stimulated. New facts suggest in tur other facts and point to unsuspected relations betwee things that have long been known. Bayliss and Star ling's discovery of a natural chemical stimulant which induces secretion of the pancreas led directly to the explanation of continued gastric secre to the explanation of continued gastric secre
tion, and also to finding the marvelous mechanism tion, and also to finding the marvelous mechanism
which the mammary glands are prepared for the giv ing of milk. Thus, though the interests of the ma of science seem at the moment narrow and restricted they may nevertheless lead his thought out into man diverse realms of knowledge. These excursions of the imagination offer repeated suggestions for fresh adventure. The look therefore is always forward to what may be seen when the next sten is taken. Seeking new things becomes in time a fixed habit. Past achievements neither satisfy interest nor hold attention --they become fused with the established routin from which it is a happiness to escape. The chance of beholding unsuspected wonders, or the possibility of finding that something imagined is really true is the zest and interest which are among the best rewards of the investigator.

Iuch happiness is found also in that single-minded- ness, which, as we have seen, is one of the prime conditions in the pursuit of knowledge. It implies free-
dom from bigotry and prejudice, freedom from many dom from bigotry and prejudice, freedom from many of the influences and motives that to their regret men feel compelled to respect for purposes of prudence or of discovering and telling the truth, only tends to distract the mind of the investigator from his absorbing work. Faraday, whose life as a man of science was near perfection, wrote:

"Do not many fail because they look rather to the renown to be acquired than to the pure acquisition of knowledge and the delight which the contented mind has in acquiring it for its own sake? I am sure I have seen many who would have been good and suc cessful pursuers of science and have gained themselves a high name, but that it was the name and the reward they were always looking forward to-the reward of the world's praise. In such there is always a shade of envy or regret over their minds, and I can not imagine a man making discoveries in science under these feelings."

Single-mindedness involves also a relative indifference to those motives of money-getting which prevail not measured by money standards. And yet research flourishes best where there is free time to spend in flourishes best where there is free time to spend in
thought and experiment. This time element is essential. The investigator may be made to dwell in a garret, he may be forced to live on crusts and wear dilapidated clothes, he may be deprived of social recognition, but if he has time, he can steadfastly devote himself to research. Take away his free time,
and he is utterly destroyed as a contributor to knowledge.

Free time and absence of the money motive, however, are found together only among the indolent poor and the indolent rich; and the observation has been made that neither of these classes is likely to contribute men of science. The industry of the investigator which results in new knowledge-knowledge in its unprofitable infancy-does not possess commercial value. Until recently indeed any value of research had not been recognized. In the unappreciative past deplorable instances were known of struggles with poverty and want, going hand in hand with persistent loyalty to truth-seeking. Now, however, accumulated wealth is giving leisure for men to carry on their investigations free from the may not be much, but it is sufficient to permit them to look upon the scramble for wealth without envy or regret.

Fortunately, the provisions which enable men io pursue careers in science are found mainly in great universities, through which a stream of youth is constantly passing. There men who are moved by the instinct of investigation usually find their most con-
genial surroundings. Freedom of inquiry is the genial surroundings. Freedom of inquiry is the
ancient tradition of the university spirit, leisure is recognized as a requisite for meditative observation, and the youth who resort to these centers of learning can be awakened to wonder at nature's hidden secrets, and can be stimulated to undertake with ardor the struggle to possess them. The peculiar richness of struggle to possess them. The peculiar richness of
university life flows from memories of the transforming powers of the progressive and original minds who have by their eagerness for the truth and their freedom from worldliness inspired their students with their own ideals.

The greatest compensation, after all, for the truth seeker is the discovery of the truth. The value of labor that brings a revelation of new knowledge does not cease with the day; it remains as a permanent acquisition for the race. There is really great satisfaction to the investigator in this thought of the "durable results of the perishable years." But not only because of the permanence of truth is there pleasure in discovery-it is the marvel of beholding fascinates men of science, and through difficulties and repeated disappointments holds them to the search. Only he who has had the experience knows the thrill that comes when that which was imagined proves to be true. One who was in Faraday's laboratory when the influence of the earth's magnetism on a wire
conducting an electric current was first tested, has conducting an electric current was first tested, has see, do you see, do ce Faraday exclaimed, 'Do you revolve, and I shall never forget the enthusiasm " $3 x-$ pressed in his face and the sparkling in his eyes." Kepler knew the joy which rewards the scientific discoverer when he completed the evidence that estab lished his third law of planetary motion. Even on whose pulses have not quickened with the excitement of discovery can understand perhaps how he must ave felt as he burst into triumphant exultation:

"What I prophesied two-and-twenty years ago

What sixteen years ago I urged as a thing to be of my life to astronomical contemplations, at length
I have brought to light and recognized its truth beyond my most sanguine expectations. It is not eighteen months since 1 got the first glimpse of light, three months since the dawn very few days since the unveiled sun burst upon me. Nothing holds me; I will Indulge my sacred fury. If you forgive me, I rejoice; if you are angry, I can bear it. The die is cast, the book is written, to be read either now or by posterity, I care not which. It may well wait a century for a reader, as God has waited six thousand years for an observer."

The scientific investigator may not seek particularly for knowledge which can meet at once some direct his effort toward that which will for the to ment properly gratify an absorbing interest of his mind. If the new knowledge has, when discovered, an immediate practical value, so much the better; but the direct search for understanding has certainly always proved the most effective motive in scientific labors. Because of this attitude the investigator should not be regarded as self-centered, or neglectful of duties to the general good. He is serving best his own generation in so far as he makes his standard of work thorough and honest. In so far as he does that, he is serving best future generations as well, for only thus can the results of his work be used later as a basis for further advancement. And since the interrelations of phenomena are so manifold the conviction is justified that every bit of honest work can finally be utilized in forming the body of truth. Although the investigator may labor, therefore, primarily to satisfy his own curiosity, and to secure for his craftsmanship that inner approval sought by every conscientious worker, nevertheless he is making per. manent additions to the world's values. There is about his life, as Prof. Royce has noted, 'an element of noble play. . . . One plays with silk and glass and amber, with kites that one flies beneath thunder clouds, with frog legs and with acid. The play is a mere expression of a curiosity which former centuries might have called idle. But the And so it is everywhere with our deeper curiosity. There is a sense in which it is all superfluous. Its immediate results seem but vanity. One could surely live without them, yet for the future and for the spiritual life of mankind, these results are destined to become of vast import."

Sometimes the worker in science lives to see his services used for the relief of human need. When Davy's studies of combustion enabled him to invent the safety lamp, he gave the invention freely to the world. He knew then that thenceforth for all time world. He knew then that thenceforth for all time the dangers of destruction. There is no realm, however, in which the deep satisfaction of seeing discovery applied to human service is more likely to ie experienced than in the realm of medical research. Consider how great must have been the joy of Pasteur and of Lister when they realized that the consequences of their investigations must lessen forever plague and pestilence and pain in men, and in the lower animals as well, and must permanently remove much of the blind struggle against mysterious agencies of disease and death. The letter which Walter Reed wrote to his wife on New Year's eve, 1900, at the end of his experiments on the transmission of yellow fever, tells something of the joy of such service- "The prayer "that has been mine for twenty years," he concludes, time to do something to alleviate human suffering, has been granted! A thousand Happy New Years." And a thousand happy new years there will be for thousands of men and women and children, because of that one research in Cuba.

Through the employment of methods of scientific inquiry to medical problems more progress has been made during the past sixty years toward an understanding of the nature of diseases and their control than had been made in the previous twenty-three centuries. Think for a moment of what has been learned about diphtheria and tetanus, about meningitis and rabies, about tuberculosis and syphilis, about dysentery and cholera and typhoid fever. How fundamentally our attitude toward these diseases has :altered as the discoveries of medical investigators have given us insight and powers to control. What great progress we have already made in this relatively short must not forget that there are immense labors yet to be accomplished. We are yet surrounded by innumerable mysteries, which can only be solved by persistent research. Not all men are fitted by temperament or training to engage in this great work, but more are thus fitted, I am sure, than are awakened to its opportunities. For those of you who are ready, here is a challenge to the supreme use of all your powers-to your imagination, your ingenuity, your interested service. 